\title{
OECD Ülkelerinde Sağlık Harcamalarının Yakınsaması: Kırılmalı Fourier Birim Kök Testinden Bulgular
}

\section{Convergence of Health Expenditures in OECD Countries: Evidence from Fourier Unit Root Test with Break}

\author{
Fatma KIZILKAYA, Malatya Turgut Özal Üniversitesi, Türkiye, fatma.kizilkaya@ ozal.edu.tr \\ Orcid No: 0000-0002-1028-9341 \\ Mehmet DAĞ, Siirt Üniversitesi, Türkiye, mehmetdag323@gmail.com \\ Orcid No: 0000-0003-2206-2184
}

Öz: Ekonomik göstergelerden biri olan sağlık harcamaları ve harcamaların zaman içinde nasıl değ iştiğ $i$ ülkelerin ekonomik koşulları, demografik yapısı, sağlıkla ilgili politikaları, teknoloji, sağlık sektörünün yapısı, tüketici tercihleri gibi birçok faktöre bağlıdır. Bu çalışmada 1975-2019 dönemi verileri kullanılarak OECD ülkelerinde kişi başı sağlık harcamalarının yakınsamasını incelenmektedir. Ekonometrik yöntem olarak Furuoka (2017) tarafindan önerilen birim kök prosedürü kullanılmıştır. Yapılan ekonometrik analiz sonucunda 17 OECD ülkesi için yakınsama hipotezinin geçerli olduğu sonucuna ulaşılmıştır.

Anahtar Kelimeler: OECD Ülkeleri, Să̆lık Harcamaları, Yakınsama Hipotezi, Birim Kök Testi

JEL Sinıflandirmasi: C22, K32, I10

\begin{abstract}
Health expenditures, which are one of the economic indicators, and how the expenditures change over time depend on many factors such as the economic conditions, demographic structure, health-related policies, technology, structure of the health sector and consumer preferences of the countries. This study examines the convergence of per capita health expenditures in OECD countries using data for the 1975-2019 period. Unit root procedure proposed by Furuoka (2017) is used as econometric method. As a result of the econometric analysis, it is concluded that the convergence hypothesis is valid for 17 OECD countries.
\end{abstract}

Keywords: OECD Countries, Healthcare Spending, Convergence Hypothesis, Unit Root Test

JEL Classification: C22, K32, I10

\section{Giriş}

Yapılan birçok iktisadi çalışma insana yapılan yatırımların ekonomik büyümede önemini ortaya koymaktadır. Ekonomik büyümenin önemli faktörlerinden biri olan insan bir beşeri sermayedir. Beşeri sermaye, toplumun sahip olduğu eğitim düzeyi ve sağlik durumu gibi kavramları ifade etmek için kullanılmaktadır. Eğitim ve sağlık yoluyla beşeri sermayenin artırılması, ülkelerin ekonomik olarak gelişmesi için gereklidir. Beşeri sermayenin temel bileşenlerinden biri olan sağlık, bilgi düzeyi ve verimliği artırmadaki rolü açısından oldukça önemlidir. Çünkü ancak sağlıklı bir nüfus beşeri sermayeye katkıda bulunabilmektedir.

Ampirik çalışmalarda doğuşta yaşam beklentisi ve sağlık harcamaları sağlık göstergeleri olarak sıklıkla kullanılmaktadır. İktisat literatüründe özellikle büyüme teorisi içerisinde ele alınan sağlık harcamaları, ekonomik kalkınmanın göstergelerinden biri olmakla birlikte kamu harcamalarında önemli bir paya sahiptir. Sağlık harcamalarının birçok gelişmiş ülkede hızla 
artığı gözlenmektedir. Kişi başına düşen reel gelirlerin artması, teknolojik yenilikler ve yaygın sağlık sigortaları ve nüfusun yaşlanmasının genellikle sağlık harcamalarının büyümesi üzerinde önemli etkiler yarattığı kabul edilmektedir. Kişi başına gelir arttıkça yaşamı iyileştiren ve ömrü uzatan yeni tıbbi teknolojilere olan ihtiyaçta artmaktadır (Nghiem ve Connelly, 2017:2). Bu nedenle sağlık harcamalarının davranışına ilişkin bilgi edinmek oldukça önemli bir konudur. Sağlık harcamaları ile ilgili yapılan çalışmalar incelendiğinde sağlık harcamalarındaki artışının nedenleri, ekonomik büyüme üzerindeki etkisi ve politika sonuçları gibi birçok yönden araştırıldığı görülmektedir.

Yüksek gelirli ekonomilerde, ekonomik büyüme giderek yavaşlayacak ve düşük gelirli ülkelerin yüksek gelirli ülkelerden daha hızlı büyüyecekleri böylece zamanla kişi başına gelir düzeylerinin birbirine yakınlaşacağı neoklasik büyüme modelinin öngörülerindendir. Literatürde bu görüş yakınsama hipotezi olarak bilinmektedir. Bu hipoteze göre büyüme faktörlerinin (yatırım, fiziksel sermaye gb.) düşük gelirli ülkelerde yüksek gelirli ülkelerden daha etkin olduğu düşünülmektedir. Yakınsama hipotezinin üç ana kaynağı olduğu ileri sürülmektedir. Bunlar; teknolojik yayılım, Neoklasik büyüme modeli ve küreselleşmedir (Rassekh, 1998: 88). Bir ülkedeki sağl1k harcama seviyesi ve bunun zaman içinde nasıl değiştiği ekonomik koşullar, demografik yapı, sağlıkla ilgili politikalar, teknoloji, sağlık sektörünün yapısı, tüketici tercihleri gibi birçok faktöre bağlıdır. Benzer gelişmişlik düzeyine sahip olan ülkelerin zamanla sağlık harcamalarının birbirine yakınsaması daha olasıdır. Literatürde $\beta$ ve $\delta$ yakınsaması olmak üzere iki tür yakınsama yaklaşımı bulunmaktadır. $\beta$ yakınsaması fakir ülkelerin zengin ülkelerden daha hızlı büyümesi olarak tanımlanabilir. $\beta$ yakınsama mutlak ve koşullu yakınsama olmak üzere ikiye ayrılır. Mutlak yakınsamada, ekonomilerin teknoloji, kurumsal yapı, tasarruf oranı gibi faktörler açısından homojen olduğu varsayılır. Koşullu yakınsamada ise bu tür farklılıkları yansıtacak değişkenler modele eklenir. $\delta$ yakınsaması ise, ekonomilerin kişi başına gelirlerinin veya harcama yayılımının incelenmesine dayanır. Yayılım ölçüsü olarak standart sapma kullanılmaktadır. Standart sapmanın zamana bağlı olarak azalması yakınsamaya, artması ise uzaklaşmaya işaret etmektedir. $\sigma$-yakınsaması, bir grup ekonominin reel kişi başına gelirleri arasındaki farkın kapanması olarak tanımlanmaktadır (Sala-i-Martin, 1996:1020).

Yakınsama hipotezi geleneksel yöntemlerin yanı sıra birim kök testleri ile de test incelenebilmektedir. Bazı çalışmalar, $\beta$ yakınsamasında bazı eksiklikler olduğunu belirterek ve koşullu yakınsama için birim kök testi yaklaşımlarını kullanmanın daha doğru olduğunu savunmuştur (Evans ve Karras, 1996:260; Quah, 1996:1356). Yakınsaması incelenen değişken, birim kök içermiyorsa ele alınan değişkendeki şoklar geçici bir etkiye sahiptir ve 
yakınsama hipotezi geçerlidir. Fakat değişkenler birim kök içeriyorsa şoklar kalıcı etkiye sahip olacak ve 1raksamaya neden olacaktır (Narayan, 2007:994).

$\mathrm{Bu}$ çalışma, dört alternatif yöntemin yakınsama hipotezini test etmek için ayrı ayrı uygulandığı ve ardından en uygun modeli belirlemek için F-testlerinin uygulandığ yaklaşım öneren Furuoka (2017) birim kök testini kullanarak yakınsama hipotezi üzerine yapılan mevcut araştırmalara katkıda bulunmayı amaçlamaktadır. Çalışmanın ikinci bölümünde OECD Ülkelerinde sağlık harcamalarının görünümü verilmiştir. Üçüncü bölümde konu ile ilgili literatürde yapılan çalışmalar özetlenmiştir. Dördüncü bölümde çalışmada kullanılan veri seti ve ekonometrik yöntem tanıtılmış, beşinci bölümde ise ekonometrik bulgulara yer verilmiştir. Çalışmanın altıncı ve son bölümünde ise sonuçlara yer verilmiştir.

\section{OECD Ülkelerinde Sağlık Harcamaları}

Sağlık harcamaları, son yarım yüzyılın çoğunda OECD ülkelerinde ekonomik büyümeden daha hızlı bir şekilde artmıştır. Harcamalardaki bu artışlar sağlık sonuçlarında iyileşmeye katkıda bulunmuş ve ekonomik büyüme ve istihdam için önemli bir kaynak olmuştur. Sağlık harcamalarındaki artışların tahminleri, ülkelere sağlı harcamalarının genel ekonomik büyümeye veya bir ülkenin nüfusuna kıyasla ne kadar hızlı ve ne kadar artabileceğine ilişkin bir perspektif sağlayabilmektedir. OECD genelinde, 2015 yılında \% 8.8 olan sağlık harcamalarının GSYH içindeki payının 2030 yılına kadar \% 10.2'ye yükseleceği tahmin edilmektedir. 2015-2030 yılları arasında sağlık harcamasının Türkiye ve Kore'de yılda \% 4'ten fazla artması beklenirken, Belçika, Almanya, İtalya, Japonya ve Portekiz'de ise yılda \% 2'den daha az artması beklenmektedir. (OECD Indicators, 2019,160-166). Grafik 1'de OECD ülkelerinin 1975, 1985, 1995, 2000, 2010 ve 2019 yıllarındaki sağlık harcamaları verilmiştir. 

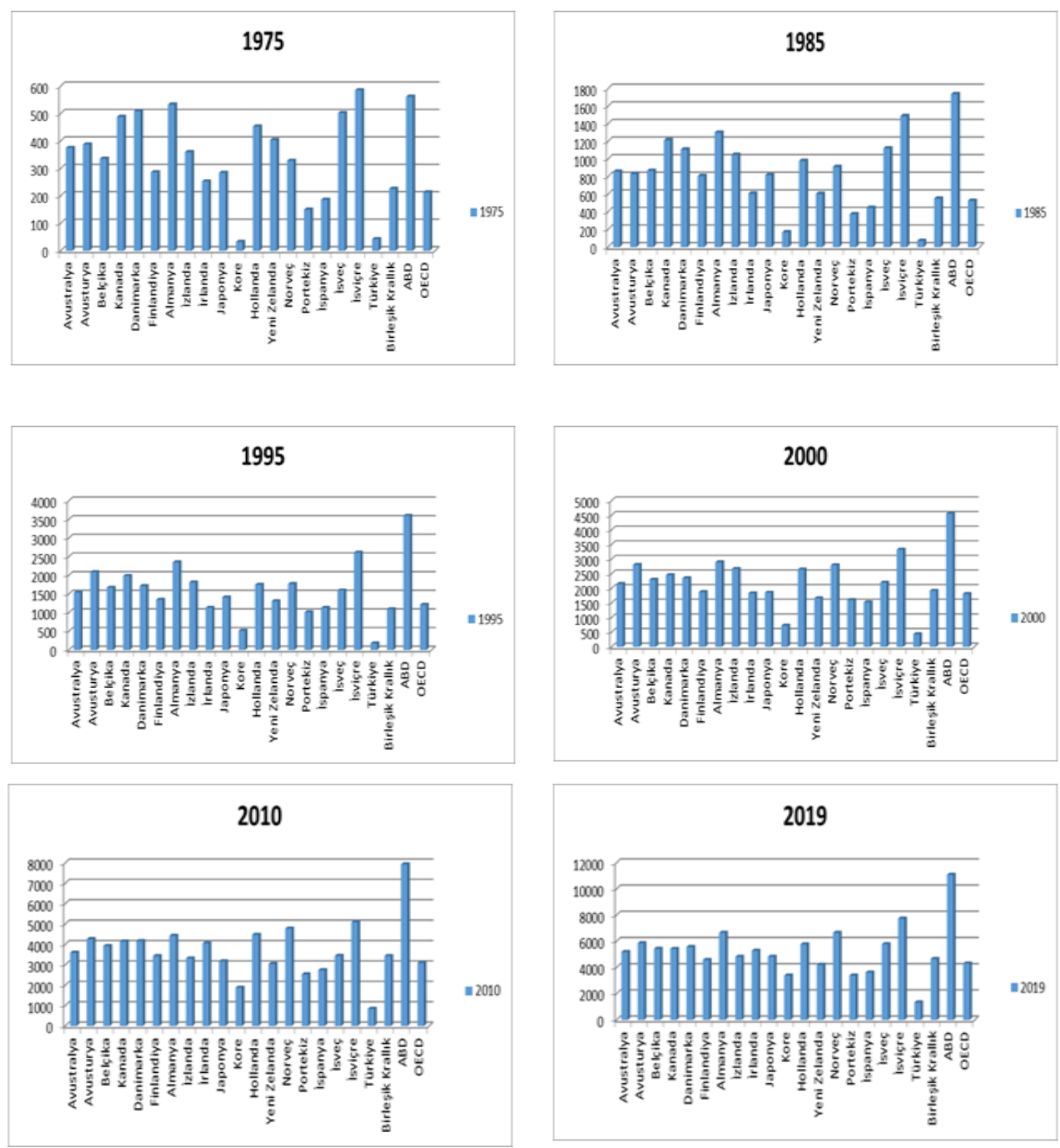

Grafik 1. OECD Ülkeleri Sağlık Harcamaları

OECD ülkelerinde, 1975-2000 yıllarında en çok sağlık harcaması yapan ülkelerin İsviçre, ABD ve Almanya; 2000-2019 yıllarında ise ABD, İsviçre ve Norveç olduğu görülmektedir. $\mathrm{Bu}$ dönemlerde en az harcama yapan ülkelerin Portekiz, Kore ve Türkiye olduğu görülmektedir. Grafik 2'de kişi başı sağlık harcamalarının OECD ortalaması ile Türkiye'nin kişi başı sağlık harcamalarının karşılaştırılması verilmiştir. 


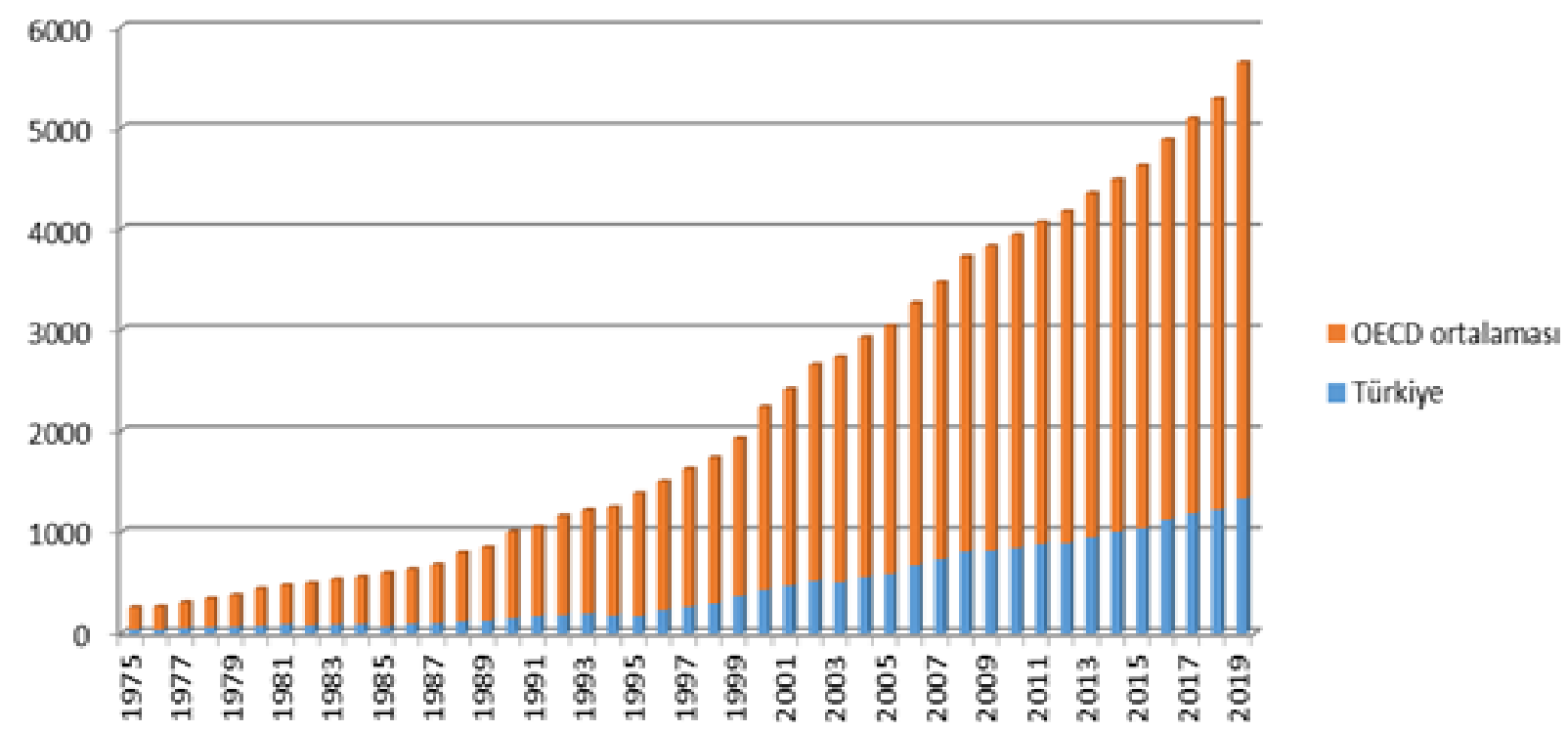

Grafik 2. OECD Ülkeleri Kişi Başı Sağlık Harcamaları Ortalaması ile Türkiye'nin Kişi Başı

Sağlık Harcamalarının Karşılaştırılması

Grafikten görülebileceği gibi Türkiye'de 1975-2019 yılları arasında sağlık harcamaları sürekli artış göstermiştir. Fakat bu dönem aralığındaki bütün yıllarda OECD ülkelerinin ortalama sağlık harcamalarının altında sağlık harcaması yapmıştır.

\section{Literatür}

Literatürde sağlık harcamaları serisinin yakınsamasını araştırmaya yönelik yapılan ampirik çalışmalar incelenerek Tablo 1'de özetlenmektedir. Literatüre bakıldığında panel veri analizi ağırlıklı olarak kullanıldığı görülmektedir. Bu çalışmada literatürden farklı olarak zaman serisi analizi kullanılmıştır. Gerek yöntem farklılığı gerek ele alınan dönem açısından çalışmanın literatüre katkı sağlaması beklenmektedir.

Tablo 1. Literatür Özeti

\begin{tabular}{|l|l|l|l|}
\hline Yazar(lar) & $\begin{array}{l}\text { Ülke (Grubu) - } \\
\text { Dönem }\end{array}$ & $\begin{array}{l}\text { Kullanılan } \\
\text { Ekonometrik } \\
\text { Yöntem }\end{array}$ & Sonuç \\
\hline Nixon (1999) & $\begin{array}{l}\text { AB Ülkeleri } \\
(1960-1995) \\
\text { y1llık }\end{array}$ & $\begin{array}{l}\beta \text { ve } \sigma \text { yakınsama } \\
\text { analizi }\end{array}$ & $\begin{array}{l}\text { 1980-1995 yılları için Beta, 1960- } \\
\text { 1995 y1lları için sigma yakınsamasi } \\
\text { vardır. Yakınsama hipotezinin geçerli } \\
\text { olduğu sonucuna ulaş1lmıştır. }\end{array}$ \\
\hline $\begin{array}{l}\text { Hitiris ve Nixon } \\
(2001)\end{array}$ & $\begin{array}{l}\text { AB Ülkeleri } \\
(1980-1995) \\
\text { y1llık }\end{array}$ & $\begin{array}{l}\beta \text { ve } \sigma \text { yakınsama } \\
\text { analizi }\end{array}$ & $\begin{array}{l}\text { Yakınsama hipotezinin geçerli olduğu } \\
\text { sonucuna ulaş1lmıştır. }\end{array}$ \\
\hline $\begin{array}{l}\text { Narayan vd. } \\
(2007)\end{array}$ & $\begin{array}{l}\text { Birleşik Krallık, } \\
\text { Kanada, Japonya, } \\
\text { İsviçre ve İspanya } \\
(1960-2000) \\
\text { y1llık }\end{array}$ & $\begin{array}{l}\text { LM, IPS panel } \\
\text { birim kök testi }\end{array}$ & $\begin{array}{l}\text { Ülkelerin sağl1k harcamalarının } \\
\text { ABD'nin sağllk harcamalarına } \\
\text { yakınsadığ1 sonucuna varıllmıştır. }\end{array}$ \\
\hline
\end{tabular}




\begin{tabular}{|c|c|c|c|}
\hline Aslan (2008) & $\begin{array}{l}19 \text { OECD Ülkesi } \\
(1970-2005) \\
\text { y1llkk }\end{array}$ & $\begin{array}{l}\text { IPS panel birim } \\
\text { kök testi }\end{array}$ & $\begin{array}{l}\text { Yakınsama hipotezinin geçerli } \\
\text { olmadığı sonucuna varılmıştır. }\end{array}$ \\
\hline Kerem vd. (2008) & $\begin{array}{l}\text { AB-8, AB-12 ve } \\
\text { AB-15 Ülkeleri } \\
\text { (1992-2004) } \\
\text { y1llk }\end{array}$ & $\begin{array}{l}\beta \text { ve } \sigma \text { yakınsama } \\
\text { analizi }\end{array}$ & $\begin{array}{l}\text { Sağlık harcamalarının GSYH } \\
\text { içerisindeki payına ilişkin } \beta \\
\text { yakınsaması bulgusu elde edilmiştir }\end{array}$ \\
\hline Wang (2009) & $\begin{array}{l}\text { ABD Eyaletleri } \\
(1980-2004) \\
\text { y1ll1k }\end{array}$ & $\begin{array}{l}\beta \text { ve } \delta \text { yakınsama } \\
\text { analizi }\end{array}$ & $\begin{array}{l}\text { Yakınsama hipotezinin geçerli olduğu } \\
\text { sonucuna ulaşılmıştır. }\end{array}$ \\
\hline $\begin{array}{l}\text { Panopoulou ve } \\
\text { Pantelidis (2011) }\end{array}$ & $\begin{array}{l}19 \text { OECD Ülkesi } \\
(1972-2006) \\
\text { y1llık }\end{array}$ & $\begin{array}{l}\text { Phillips ve Sul } \\
\text { (2007) yöntemi }\end{array}$ & $\begin{array}{l}17 \text { OECD ülkesi için yakınsama } \\
\text { hipotezinin geçerli olduğu sonucuna } \\
\text { ulaşılmıştır. }\end{array}$ \\
\hline $\begin{array}{l}\text { Tülümce ve } \\
\text { Zeren (2013) }\end{array}$ & $\begin{array}{l}18 \text { OECD Ülkesi } \\
(1980-2008)\end{array}$ & $\begin{array}{l}\text { Peseran (2007) } \\
\text { panel birim kök } \\
\text { testi }\end{array}$ & $\begin{array}{l}\text { Bebek ölüm oranı ve doğum anında } \\
\text { yaşam beklentisinin durağan } \\
\text { olduğunu, sağlık harcamalarının } \\
\text { GSYH içindeki payının ise durağan } \\
\text { olmadığını yani yakınsama olmadığ } \\
\text { sonucuna ulaşmışlardır. }\end{array}$ \\
\hline Lau vd. (2014) & $\begin{array}{l}14 \text { AB Ülkesi } \\
(1970-2008)\end{array}$ & $\begin{array}{l}\text { Doğrusal } \\
\text { Olmayan IPS } \\
\text { panel birim kök } \\
\text { testi }\end{array}$ & $\begin{array}{l}\text { Yakınsama hipotezinin geçerli } \\
\text { olmadığı sonucuna ulaşmışlardır. }\end{array}$ \\
\hline Payne vd. (2015) & $\begin{array}{l}19 \text { OECD Ülkesi } \\
(1972-2008)\end{array}$ & $\begin{array}{l}\text { RALS-LM Birim } \\
\text { Kök Testi }\end{array}$ & $\begin{array}{l}\text { OECD ülkesinde kişi başı sağlık } \\
\text { harcamalarında yakınsama olduğunu } \\
\text { gözlemlenmiştir. }\end{array}$ \\
\hline Pekkurnaz (2015) & $\begin{array}{l}22 \text { OECD Ülkesi } \\
(1980-2012)\end{array}$ & $\begin{array}{l}\text { IPS, doğrusal } \\
\text { olmayan simetrik } \\
\text { ve asimetrik } \\
\text { panel birim kök } \\
\text { testleri }\end{array}$ & $\begin{array}{l}\text { Yakınsama hipotezinin geçerli olduğu } \\
\text { sonucuna ulaşılmıştır. }\end{array}$ \\
\hline $\begin{array}{l}\text { Odhiambo vd. } \\
\text { (2015) }\end{array}$ & $\begin{array}{l}\text { Sahraaltı Afrika } \\
\text { Ülkeleri } \\
(2001-2011)\end{array}$ & $\begin{array}{l}\text { GMM-IV panel } \\
\text { veri analizi }\end{array}$ & $\begin{array}{l}\text { Yakınsama hipotezinin geçerli } \\
\text { olduğuna dair kanıtlar bulunmuştur. }\end{array}$ \\
\hline Zhang vd. (2016) & $\begin{array}{l}\text { Çin } \\
(2003-2007) \\
\end{array}$ & $\begin{array}{l}\text { Regresyon } \\
\text { Analizi }\end{array}$ & $\begin{array}{l}\text { Kısa ve uzun vadeli yakınsama olduğu } \\
\text { sonucuna ulaşmışlardır. }\end{array}$ \\
\hline $\begin{array}{l}\text { Apergis vd. } \\
(2017)\end{array}$ & $\begin{array}{l}\text { 50 ABD Eyaleti } \\
(1966-2009)\end{array}$ & $\begin{array}{l}\text { Modifiye edilmiş } \\
\text { IPS testi }\end{array}$ & $\begin{array}{l}\text { Yakınsama hipotezinin geçerli olduğu } \\
\text { sonucuna ulaşılmıştır. }\end{array}$ \\
\hline $\begin{array}{l}\text { Albulescu vd. } \\
\text { (2017) }\end{array}$ & $\begin{array}{l}6 \text { AB Ülkesi } \\
(1972-2013)\end{array}$ & $\begin{array}{l}\text { Cavaliere (2005) } \\
\text { ve Cavaliere ve } \\
\text { Xu (2014) birim } \\
\text { kök testi }\end{array}$ & $\begin{array}{l}\text { Sağlık harcamalarının GSYH'ya oranı } \\
\text { açısından önemli bir yakınsama } \\
\text { olmadığı sonucuna ulaşılmıştır. }\end{array}$ \\
\hline $\begin{array}{l}\text { Nghiem ve } \\
\text { Connelly (2017) }\end{array}$ & $\begin{array}{l}\text { OECD Ülkeleri } \\
(1975-2004)\end{array}$ & $\begin{array}{l}\text { Phillips ve Sul } \\
\text { (2007) yöntemi }\end{array}$ & $\begin{array}{l}\text { Yakınsama hipotezinin geçerliliğine } \\
\text { dair kanıt olmadığı sonucuna } \\
\text { ulaşılmıştır. }\end{array}$ \\
\hline Şahin (2018) & $\begin{array}{l}\text { MENA Ülkeleri } \\
(1995-2014)\end{array}$ & $\begin{array}{l}\text { CADF Panel } \\
\text { Birim Kök Testi }\end{array}$ & $\begin{array}{l}\text { Yakınsama hipotezinin geçerli } \\
\text { olmadığı sonucuna ulaşılmıştır. }\end{array}$ \\
\hline $\begin{array}{l}\text { Akarsu vd. } \\
\text { (2019) }\end{array}$ & $\begin{array}{l}18 \text { OECD Ülkesi } \\
(1979-2016) \\
\text { y1ll1k }\end{array}$ & $\begin{array}{l}\text { Panel KSS, } \\
\text { PTAR, } \\
\text { PANKPSS panel } \\
\text { birim kök testleri }\end{array}$ & $\begin{array}{l}\text { Sadece kişi başına düşen özel sağlık } \\
\text { harcamaları için yakınsama } \\
\text { hipotezinin geçerli olduğu sonucuna } \\
\text { ulaşılmıştır. }\end{array}$ \\
\hline $\begin{array}{l}\text { Clemente vd. } \\
\text { (2019) }\end{array}$ & $\begin{array}{l}\text { ABD Eyaletleri } \\
(1966-2014)\end{array}$ & $\begin{array}{l}\text { Phillips ve Sul } \\
\text { (2007) yöntemi }\end{array}$ & $\begin{array}{l}\text { Yakınsama hipotezinin geçerli olduğu } \\
\text { sonucuna ulaşılmıştır. }\end{array}$ \\
\hline
\end{tabular}


OECD ülkelerinin sağlık harcamalarını yakınsamasını inceleyen çalışmalara bakıldığında, kullanılan yöntemlerin ve ele alınan dönemlerin bir birinden farklı olması nedeniyle sağlık harcamalarının yakınsamasına ilişkin bir fikir birliği olmadığı görülmüştür. Ayrıca literatür incelendiğinde birçok ülke grubu için yakınsama hipotezinin panel veri analizi çerçevesinde ele alındığı ampirik çalışmaların oldukça fazla olmasına rağmen, zaman serileri analizi kullanılarak yapılan çalışmaların ise az sayıda olduğu görülmektedir (örneğin Payne ve vd. (2015)). Panel veri yöntemlerinin zaman serileri yöntemlerine kıyasla bazı avantajları bulunmakla beraber önemli dezavantajları da bulunmaktadır. Panel yöntemleri birimler arasında heterojenlik bulunduğunda veri dinamiklerinin karmaşık yönlerini gizleyebilmekte ve araştırmacıların panel birimleri hakkında doğru çıkarımlar yapmasını engelleyebilmektedir. $\mathrm{Bu}$ durumda yapısal kırılmalı, doğrusal olmayan veya daha güçlü birim kök testleri daha iyi seçenekler olabimektedir (Furuoka, 2017:1257-1260). Bu nedenle mevcut alternatifler arasından en uygun tahmin modelini belirlemek için Furuoka (2017) birim kök prosedürü basit ve tutarlı bir metodoloji sunması açısından oldukça işlevseldir.

\section{Veri Seti ve Ekonometrik Yöntem}

$\mathrm{Bu}$ çalışma 1975-2019 dönemi yıllık veriler kullanarak verilerine ulaşılabilen 21 OECD ülkesin kişi başı sağlık harcamalarının yakınsamasını incelemektedir. Çalışmada ele alınan ülkeler: Avustralya, Avusturya, Belçika, Kanada, Danimarka, Finlandiya, Almanya, İzlanda, İrlanda, Japonya, Kore, Hollanda, Yeni Zelanda, Norveç, Portekiz, İspanya, İsveç, İsviçre, Türkiye, Birleşik Krallık ve ABD. Bütün veriler OECD Sağlık (2020) veri tabanından elde edilmiştir.

Analizde kullanılacak veriler Payne vd. (2015)'nin çalışması takip edilerek aşağıdaki formül ile elde edilmiştir:

$$
y_{i t}=\ln \left(\frac{K B S H_{i t}}{\text { ortalama KBSH }}\right)
$$

Burada $K B S H_{i t}$ ele alınan her bir ülke için kişi başı sağlık harcamalarını, ortalama $\mathrm{KBSH}_{i}$ kişi başı ortalama OECD sağlık harcamalarını, ln ise doğal logaritmayı ifade etmektedir. Tüm veriler ABD doları cinsinden ele alınan veriler OECD satınalma gücü paritesi (PPP) ile düzeltilmiştir.

Çalışmada Furuoka (2017) birim kök prosedürü kullanılmıştır. Bu yaklaşım kırılmasız, yumuşak kırılmalı, keskin kırılmalı ve hem yumuşak hem keskin kırılmaların olduğu modeller arasından en uygun olanının seçilmesine dayanmaktadır. Furuoka (2017) çalışmasında dört farklı ekonometrik yöntem kullanmıştır. Bu yöntemler: Genişletilmiş Dickey-Fuller (ADF) 
testi, Fourier fonksiyonu kullanarak doğrusal olmama durumunu dikkate alan Fourier ADF (FADF) testi, keskin kırılmaları dikkate alan ADF-SB testi ve hem doğrusal olmama durumunu hem de keskin kırılmaları dikkate alan FADF-SB testidir.

Dört testin tümü için temel hipotez şu şekilde formüle edilir;

$$
y_{t}=\mu+y_{t-1}+\varepsilon_{t}
$$

Testin alternatif hipotezi için dört farklı model oluşturulmuştur:

$$
\begin{gathered}
y_{t}=\alpha+\beta t+\varepsilon_{t} \\
y_{t}=\alpha+\beta t+\gamma_{1} \sin \left(\frac{2 \pi k t}{T}\right)+\gamma_{2} \cos \left(\frac{2 \pi k t}{T}\right)+\varepsilon_{t} \\
y_{t}=\alpha+\beta t+\delta D U_{t}+\theta D\left(T_{B}\right)_{t}+\varepsilon_{t} \\
y_{t}=\alpha+\beta t+\gamma_{1} \sin \left(\frac{2 \pi k t}{T}\right)+\gamma_{2} \cos \left(\frac{2 \pi k t}{T}\right)+\delta D U_{t}+\theta D\left(T_{B}\right)_{t}+\varepsilon_{t}
\end{gathered}
$$

Burada $\beta$ eğim parametresi, $k$ fourier yapısı için frekans sayısıdır. $\gamma$ trigonemetrik terimlerin eğim parametresi, $\mathrm{t}$ deterministik trend, $\mathrm{T}$ gözlem sayısı, $\pi=3.14, \delta$ yapısal kırılma kukla değişkeninin eğim parametresidir. $\theta$ zamanda meydana gelen yapısal kırılma kukla değişkeninin eğim parametresidir ve bu kukla değişkenler şu şekilde tanımlanmaktadır;

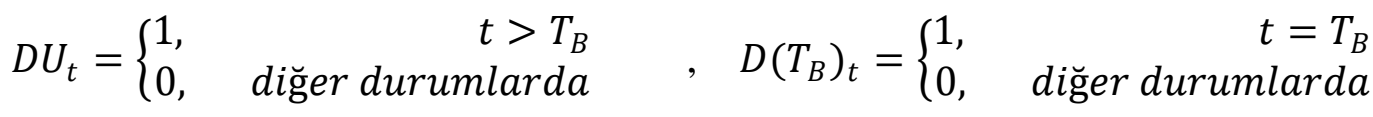

Bu modellerin tahminleri aşağıdaki denklemler ile verilmiştir:

$$
\text { Model } A: \Delta y_{t}=\mu+\beta t+\rho y_{t-1}+\sum_{i=1}^{p} c_{i} \Delta y_{t-i}+\varepsilon_{t}
$$

Model $B: \Delta y_{t}=\mu+\beta t+\gamma_{1} \sin \left(\frac{2 \pi k t}{T}\right)+\gamma_{2} \cos \left(\frac{2 \pi k t}{T}\right)+\rho y_{t-1}+\sum_{i=1}^{p} c_{i} \Delta y_{t-i}+\varepsilon_{t}$

$$
\text { Model } C: \Delta y_{t}=\mu+\beta t+\delta D U_{t}+\theta D\left(T_{B}\right)_{t}+\rho y_{t-1} \sum_{i=1}^{p} c_{i} \Delta y_{t-i}+\varepsilon_{t}
$$

Model $D: \Delta y_{t}=\mu+\beta t+\gamma_{1} \sin \left(\frac{2 \pi k t}{T}\right)+\gamma_{2} \cos \left(\frac{2 \pi k t}{T}\right)+\delta D U_{t}+\theta D\left(T_{B}\right)_{t}+\rho y_{t-1} \sum_{i=1}^{p} c_{i} \Delta y_{t-i}+\varepsilon_{t}$

Burada Model A kırılmaları ve doğrusal olmama durumunu dikkate almayan ADF modelini, Model B doğrusal olmama durumunu dikkate alan FADF modelini, Model C kırılmaları dikkate alan ADF-SB modelini, Model D ise hem kırılmaları hem de doğrusal olmama durumunu dikkate alan FADF-SB modelini ifade etmektedir.

Furuoka (2017) tarafından önerilen FADF-SB modeli hem kırılma konumuna $(\lambda)$ hem de frekansa (k) duyarlıdır. $k$ değeri en küçük kalıntı kareler toplamını veren değer olarak belirlenmektedir. FADF-SB modeli için en küçük ADF test istatistiğini veren değer, optimal 
kırılma konumu $(\tilde{\lambda})$ olarak belirlenir. Uygun frekans sayısı ve kırılma konumu aşağıdaki şekilde gösterilmektedir:

$$
\tau_{F A D F-S B}(\tilde{\lambda}, \tilde{k})=\inf \tau_{F A D F-S B}(\lambda, k)
$$

Dört farklı alternatif arasından en iyi tahmin yöntemini belirlemek için Denklem (12) ile verilen F testi kullanılmaktadır:

$$
F=\frac{\left(S S R_{0}-S S R_{1}\right) / q}{S S R_{1} /(T-S)}
$$

Burada $S S R_{1}$ kısıtlanmamış modelin, $S S R_{0}$ kısıtlı modelin kalıntı kareler toplamıdır. Ayrıca $q$ kısıtlamaların sayısını, $s$ ise kısıtsız modeldeki parametre sayısını ifade etmektedir (Furuoka, 2017:1257-1260).

\section{Ampirik Sonuçlar}

$\mathrm{Bu}$ çalışmada, sağlık harcamalarının yakınsama özelliği gösterip göstermediği, Furuoka (2017) tarafından geliştirilen birim kök testi ile analiz edilmiştir. Tablo 2'de ülkelere ait birim kök testi sonuçları verilmiştir. Tablo 3'de ise uygun modelin seçiminde kullanılan F testi sonuçları yer almaktadır.

\begin{tabular}{|c|c|c|c|c|c|c|}
\hline \multirow[t]{2}{*}{ Ülkeler } & \multirow{2}{*}{$\frac{\text { Model A }}{\text { ADF }}$} & \multirow{2}{*}{$\begin{array}{c}\text { Model B } \\
\text { FADF }\end{array}$} & \multicolumn{2}{|c|}{ Model C } & \multicolumn{2}{|c|}{ Model D } \\
\hline & & & $T_{B}, \lambda$ & ADF-SB & $T_{B}, \lambda$ & FADF-SB \\
\hline Avustralya & -0.334 & $-3.282(1)$ & $1987,0.28$ & -2.923 & $1989,0.33$ & $-4.772(1) * *$ \\
\hline Avusturya & -2.425 & $-4.409(2) * *$ & $1988,0.31$ & -3.449 & $1988,0.31$ & $-4.956(2) * *$ \\
\hline Belçika & -1.629 & $-3.652(1)$ & $1994,0.44$ & $-3.759 * * *$ & $1994,0.44$ & $-4.919(1) * *$ \\
\hline Kanada & -0.912 & $-1.864(1)$ & $1994,0.44$ & -3.167 & $2004,0.66$ & $-3.346(1)$ \\
\hline Danimarka & -0.298 & $-2.660(1)$ & $1987,0.28$ & -3.299 & $1981,0.15$ & $-3.691(1)$ \\
\hline Finlandiya & -1.360 & $-0.241(2)$ & $1991,0.37$ & $-5.810 *$ & $1992,0.40$ & $-5.534(2) *$ \\
\hline Almanya & -0.234 & $-3.206(1)$ & $2009,0.77$ & -1.922 & $1988,0.31$ & $-4.646(2) * *$ \\
\hline İzlanda & $-3.568 * *$ & $-3.424(1)$ & $1991,0.37$ & $-3.966 * *$ & $1989,0.33$ & $-4.678(1) * * *$ \\
\hline İrlanda & -1.357 & $-2.944(1)$ & $1999,0.55$ & -2.960 & $1987,0.28$ & $-4.204(1)$ \\
\hline Japonya & -1.421 & $-1.676(1)$ & $2010,0.80$ & $-4.010 * *$ & $2010,0.80$ & $-5.045(2) * *$ \\
\hline Kore & -2.911 & $-1.766(1)$ & $1996,0.48$ & $-4.186 * *$ & $1978,0.08$ & $-7.213(2) *$ \\
\hline Hollanda & -1.380 & $-3.454(1)$ & $1987,0.28$ & -3.328 & $1981,0.15$ & $-4.343(1) * * *$ \\
\hline Yeni Zelanda & -1.648 & $-3.205(1)$ & $2007,0.73$ & -2.954 & $1979,0.11$ & $-4.588(1) * *$ \\
\hline Norveç & $-3.590 * *$ & $-4.642(1) * *$ & $1987,0.28$ & $-6.356^{*}$ & $1987,0.28$ & $-6.896(2) *$ \\
\hline Portekiz & -2.264 & $-4.821(1) * *$ & $1985,0.24$ & $-4.269 * *$ & $1985,0.24$ & $-6.688(2) *$ \\
\hline İspanya & -2.870 & $-2.958(2)$ & $1985,0.24$ & $-3.804 * * *$ & $1987,0.28$ & $-3.831(1)$ \\
\hline İsveç & -0.405 & $-3.033(1)$ & $2010,0.80$ & $-3.741 * *$ & $2010,0.80$ & $-6.925(2) *$ \\
\hline İsviçre & -0.602 & $-3.494(1)$ & $1994,0.44$ & -2.800 & $1985,0.24$ & $-5.123(1) * *$ \\
\hline Türkiye & -1.954 & $-4.287(1) * * *$ & $1984,0.22$ & $-4.631 *$ & $1984,0.22$ & $-5.336(1) * *$ \\
\hline $\begin{array}{l}\text { Birleşik } \\
\text { Krallık }\end{array}$ & -2.339 & $-4.740(2) * *$ & $1996,0.48$ & $-4.794 *$ & $1989,0.33$ & $-6.046(2) *$ \\
\hline ABD & -2.097 & $-1.727(1)$ & $1994,0.44$ & $-4.030 * *$ & $1999,0.55$ & $-3.434(2)$ \\
\hline
\end{tabular}

Tablo 2. Birim Kök Testi Sonuçları

Not: Parantez içerisindeki değerler, uygun frekanslar sayılarını göstermektedir. ${ }^{*}, * *$ ve $* * *$ sırasıyla $\% 1, \% 5$ ve $\% 10$ düzeyinde anlamlılığı göstermektedir. $\mathrm{T}_{\mathrm{B}}$ ve $\lambda$ sırasıyla kırılma noktasını ve kırılma pozisyonunu göstermektedir. 
ADF test sonuçlarına bakıldığında testin İzlanda ve Norveç hariç 19 ülke için birim kök temel hipotezini reddetmede başarısız olduğu görülmüştür. ADF testi sonuçlarına göre 19 ülke için yakınsama hipotezinin geçerli olmadığı sonucuna ulaşılır. FADF test sonuçlarına bakıldığında Avusturya, Norveç, Portekiz, Türkiye ve Birleşik Krallık dışındaki 16 ülke için birim kök temel hipotezini reddetmede başarısız olduğu görülmüştür. FADF sonuçlarına göre 16 ülke için yakınsama hipotezinin geçerli olmadığı sonucuna ulaşılır. ADF-SB test sonuçları incelendiğinde Belçika, Finlandiya, İzlanda, Japonya, Kore, Norveç, Portekiz, İspanya, İsveç, Türkiye, Birleşik Krallık ve ABD olmak üzere 12 ülke için birim kök temel hipotezi reddedilmiştir. ADF-SB test sonuçlarına göre söz konusu bu ülkeler için yakınsama hipotezinin geçerli olduğu sonucuna ulaşılmıştır. FADF-SB test sonuçları incelendiğinde Kanada, Danimarka, İrlanda, İspanya ve ABD dışındaki 16 ülke için birim kök temel hipotezi reddedilmiştir. FADF-SB test sonuçlarına göre bu 16 ülke için yakınsama hipotezinin geçerli olduğu sonucuna ulaşılmıştır.

$\mathrm{Bu}$ yöntem en iyi tahmin yöntemini belirlemek için beş tane $\mathrm{F}$ testi uygulamaktadır. Birinci F testinin amacı FADF ile ADF yönteminin bulgularını karşılaştırmaktır. Test doğrusallık temel hipotezini reddederse FADF prosedürü kullanılarak devam edilir. İkinci $\mathrm{F}$ testinin amacı ADF-SB testinden elde edilen bulguların ADF testi sonuçlarıyla karşılaştırılmasıdır. $\mathrm{Bu}$ F-testinin yapısal kırılma olmadı̆̆ını belirten temel hipotezin reddedilmemesi durumunda, ADF-SB testi analiz için tercih edilen prosedür olacaktır. Üçüncü, dördüncü ve beşinci F testleri, FADF-SB testinden elde edilen bulguların diğer üç testin sonuçlarıyla, yani ADF testi, FADF testi ve ADF-SB testi ile karşılaştırılmasına amaçlar. $\mathrm{Bu} F$ testleri doğrusallık hipotezini reddederse, o zaman FADF-SB testi, dört alternatif arasında en iyi tahmin modeli olacaktır. Doğrusal dışılık ve yapısal kırılma tespit edilmezse, ADF testi, analize devam etmek için en iyi seçenek olacaktır. Doğrusal olmama durumu belirlendikten sonra yapısal kırılma saptanmazsa analiz FADF testi kullanılarak devam etmelidir. Bunun tersine, yapısal bir kırılma tespit edilir ve doğrusallık varsa, ADF-SB testi en uygun tahmin modeli olacaktır. Hem doğrusal olmama durumu hem de yapısal kırılma tespit edildiğinde, analiz için FADF-SB modeli kullanılmalıdır. (Furuoka, 2017:1257-1260). 
Tablo 3. F-İstatistikleri

\begin{tabular}{|c|c|c|c|c|c|c|c|}
\hline Ülkeler & $\begin{array}{l}\text { F1 (Model } \\
\text { B vs } \\
\text { Model A) }\end{array}$ & $\begin{array}{l}\text { F2 (Model } \\
\text { C vs } \\
\text { Model A) }\end{array}$ & $\begin{array}{l}\text { F3 (Model } \\
\text { D vs } \\
\text { Model A) }\end{array}$ & $\begin{array}{l}\text { F4 (Model } \\
\text { D vs } \\
\text { Model B) }\end{array}$ & $\begin{array}{l}\text { F5 (Model } \\
\text { D vs } \\
\text { Model C) }\end{array}$ & $\begin{array}{l}\text { Uygun } \\
\text { Model }\end{array}$ & Karar \\
\hline Avustralya & 8.654 & $10.182 *$ & $7.996 * *$ & $5.389 * *$ & $15.860 *$ & Model D & Durağan \\
\hline Avusturya & $10.022 * *$ & $6.012^{* *}$ & $10.163^{*}$ & $7.145 * * *$ & $20.242 *$ & Model D & Durağan \\
\hline Belçika & $9.070 * * *$ & $6.172^{* *}$ & $8.533^{* *}$ & $5.775 * *$ & 16.804* & Model D & Durağan \\
\hline Kanada & 5.381 & $5.686^{* *}$ & $5.889 * * *$ & $5.229 * * *$ & $11.613^{*}$ & Model D & $\begin{array}{c}\begin{array}{c}\text { Durağan } \\
\text { değil }\end{array} \\
\end{array}$ \\
\hline Danimarka & 7.998 & $13.642^{*}$ & $8.516^{* *}$ & $6.697 *$ & $16.993^{*}$ & Model D & $\begin{array}{c}\text { Durağan } \\
\text { değil }\end{array}$ \\
\hline Finlandiya & $6.947 * *$ & $23.769^{*}$ & $23.495^{*}$ & $29.785^{*}$ & 46.896* & Model D & Durağan \\
\hline Almanya & $12.157 * *$ & $7.191^{* *}$ & $14.698^{*}$ & $11.002 *$ & $29.242 *$ & Model D & Durağan \\
\hline İzlanda & 1.640 & 2.122 & 3.965 & $5.881^{* * *}$ & $6.606 * * *$ & Model A & Durağan \\
\hline İrlanda & 7.425 & $5.803^{* *}$ & $7.141 * *$ & $5.241 * *$ & $14.200 *$ & Model D & $\begin{array}{c}\text { Durağan } \\
\text { değil }\end{array}$ \\
\hline Japonya & 5.314 & $9.097^{*}$ & $10.259^{*}$ & $12.162^{*}$ & $20.223^{*}$ & Model D & Durağan \\
\hline Kore & 3.565 & $4.186^{* * * *}$ & $11.185^{*}$ & $16.053 *$ & $21.386^{*}$ & Model D & Durağan \\
\hline Hollanda & 7.338 & $4.982 * * *$ & $5.762 * * *$ & $3.316 * * *$ & $11.440 *$ & Model D & Durağan \\
\hline $\begin{array}{c}\text { Yeni } \\
\text { Zelanda }\end{array}$ & 3.843 & 3.052 & 5.302 & $5.812 * *$ & $10.493^{*}$ & Model A & $\begin{array}{c}\begin{array}{c}\text { Durağan } \\
\text { değil }\end{array} \\
\text {. }\end{array}$ \\
\hline Norveç & 4.568 & $12.285^{*}$ & $7.876 * *$ & $9.250 *$ & $15.624 *$ & Model D & Durağan \\
\hline Portekiz & $10.127 * * *$ & $6.974 * *$ & $10.178^{*}$ & $7.075 * * *$ & $20.285^{*}$ & Model D & Durağan \\
\hline İspanya & 0.874 & $8.272^{* *}$ & 2.296 & 3.601 & 4.537 & Model C & Durağan \\
\hline İsveç & $12.228 * *$ & $9.666^{*}$ & $19.972 *$ & $17.419 *$ & $39.736^{*}$ & Model D & Durağan \\
\hline İsviçre & $14.900 *$ & $6.871^{* *}$ & $12.552 *$ & $6.217 * *$ & $24.921^{*}$ & Model D & Durağan \\
\hline Türkiye & 8.148 & $8.707^{*}$ & $6.720 * * *$ & $4.027 * * *$ & 13.411* & Model D & Durağan \\
\hline $\begin{array}{l}\text { Birleşik } \\
\text { Krallık }\end{array}$ & $10.662 *$ & $12.851^{*}$ & $9.000 *$ & 5.097 & $17.872^{*}$ & Model B & Durağan \\
\hline $\mathrm{ABD}$ & 4.156 & $7.886^{* *}$ & 3.075 & 1.820 & $5.971 * *$ & Model D & Durağan \\
\hline
\end{tabular}

Not: .*,** ve *** sirasıyla $\% 1, \% 5$ ve $\% 10$ düzeyinde anlamllı̆ı̆ı göstermektedir.

Tablo 3'de belirtilen F istatistikleri sonuçlarına bakıldığında İzlanda, Yeni Zelanda, İspanya ve Birleşik Krallık dışındaki bütün ülkeler için uygun modelin D olduğu sonucuna ulaşılmıştır. Ayrıca Kanada, Danimarka, İrlanda ve Yeni Zelanda ülkelerinde sağlık harcamalarına gelen şokların kalıcı olduğu ve yakınsama hipotezinin bu ülkelerde geçerli olmadığı belirlenmiştir. Avustralya, Avusturya, Belçika, Finlandiya, Almanya, İzlanda, Japonya, Kore, Hollanda, Norveç, Portekiz, İspanya, İsveç, İsviçre, Türkiye, Birleşik Krallık, ABD ülkeleri için ise sağlı harcamalarına gelen şokların geçici olduğu ve yakınsama hipotezinin geçerli olduğu sonucuna ulaşılmıştır.

Grafik 3'te ülkelere ait seriler ve yapısal değişimler verilmiştir. Keskin kırılmaları ve yumuşak kırılmaları bir arada ele alan model D'nin genel itibariyle serilere uyumunun oldukça iyi olduğu görülmektedir. 

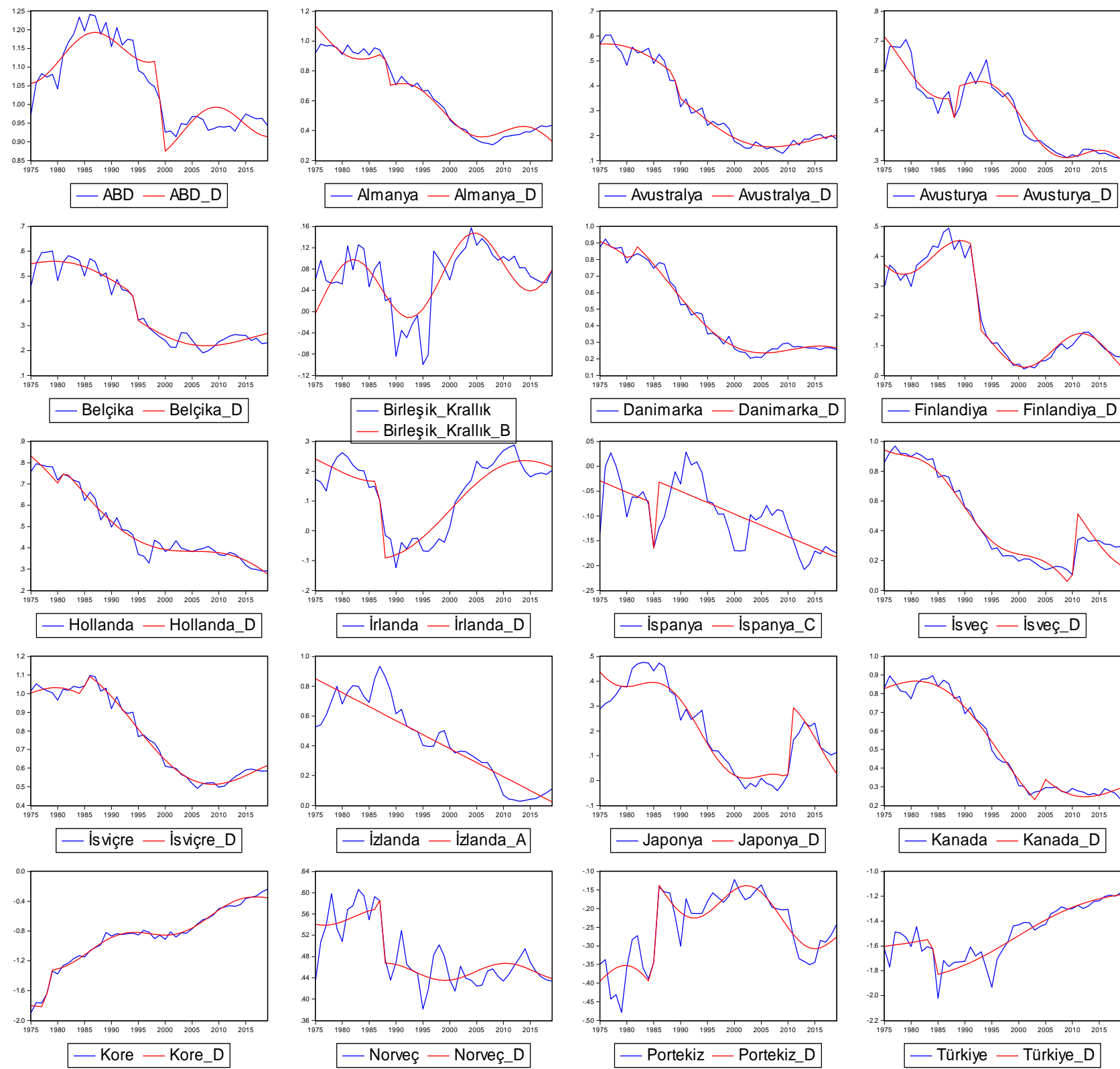

- Almanya - Almanya_D
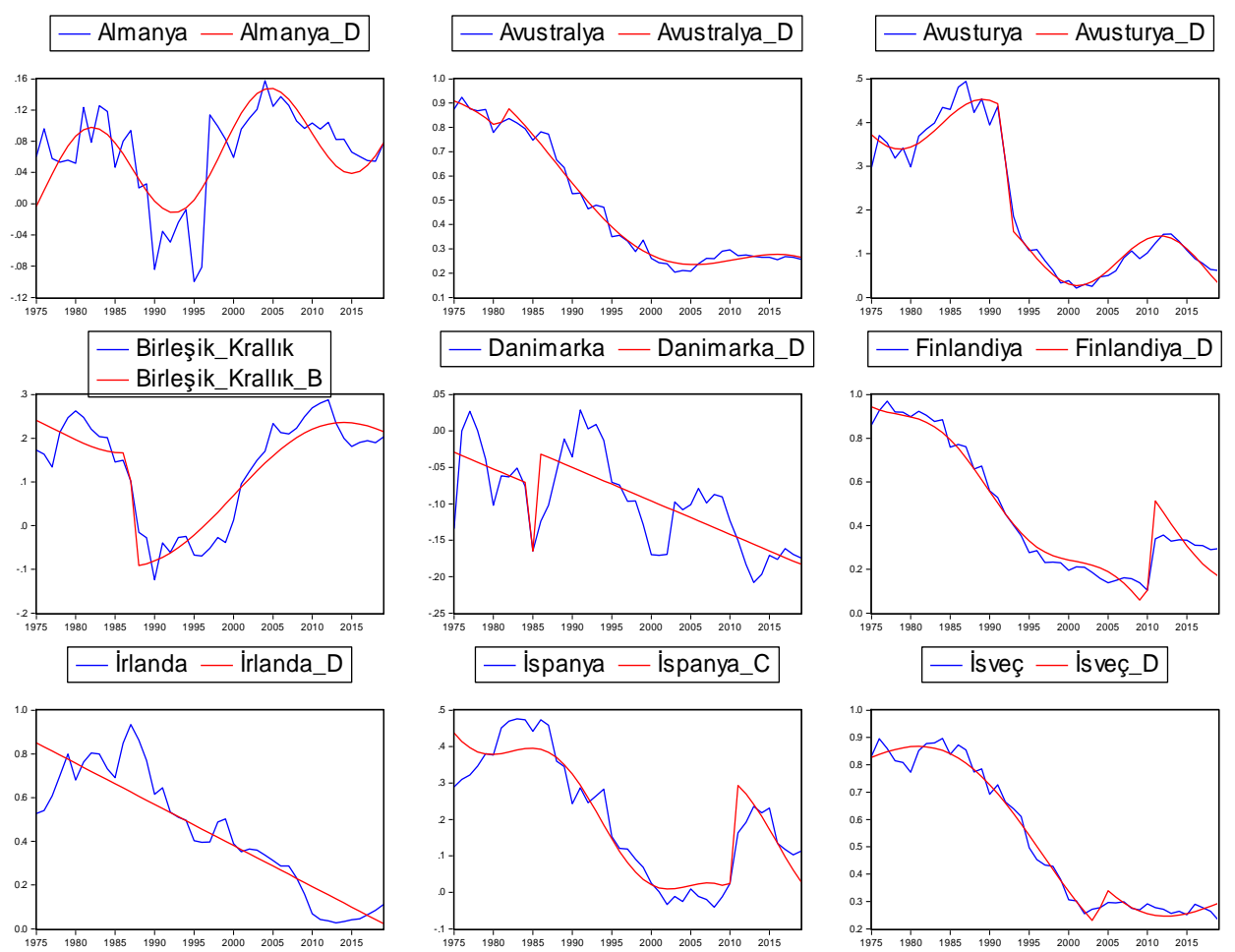

— İsveç — İsveç_D
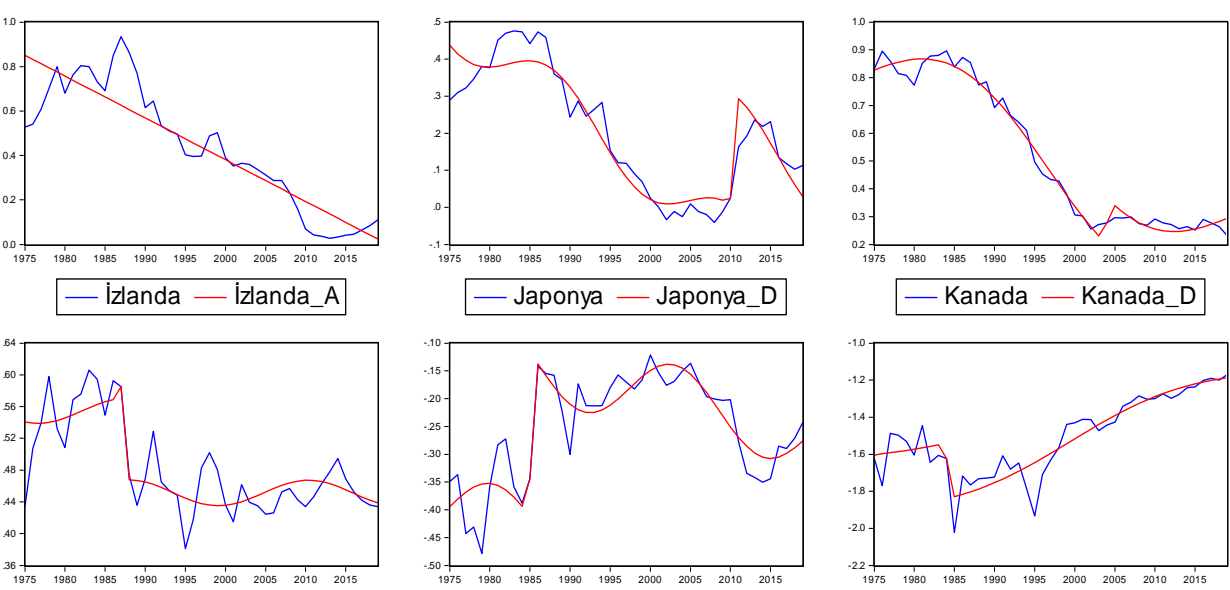

— Kanada _ Kanada_D

$$
\text { - Norveç - Norveç_D }
$$

- Portekiz — Portekiz_D
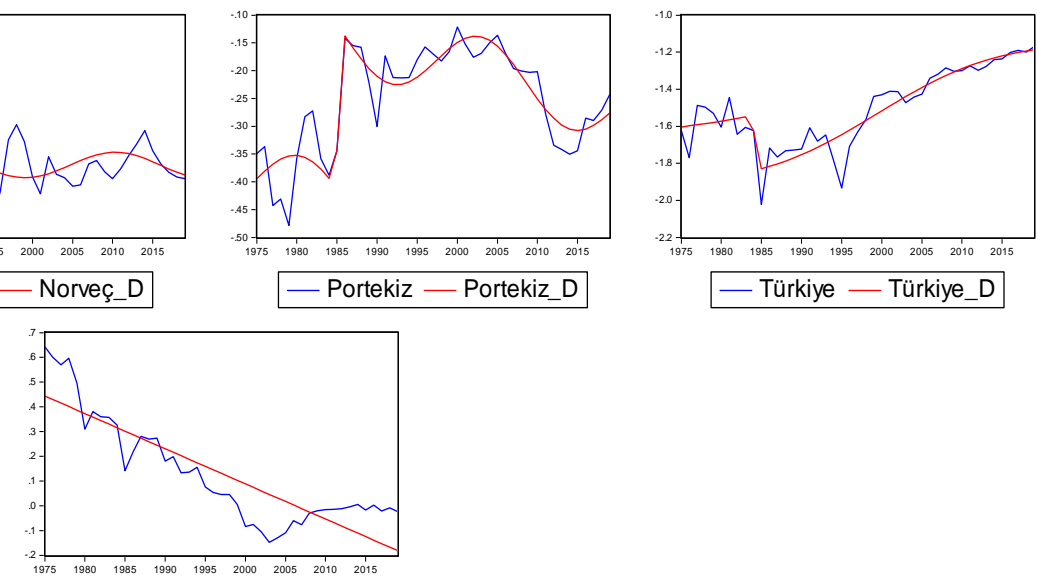

—Yeni_Zelanda —Yeni_Zelanda_A

Grafik 3. Ülkelere ait seriler ve yapısal değişimler

\section{Sonuç}

Bu çalışmada 1975-2019 yılları için 21 OECD ülkesinin sağlı harcamaları yakınsamasını incelemektedir. Dört alternatif yöntemin yakınsama hipotezini test etmek için ayrı ayrı uygulandığı ve ardından en uygun modeli belirlemek için F-testlerinin uygulandığı yeni bir yaklaşım öneren Furuoka (2017) birim kök testini kullanarak yakınsama hipotezi üzerine 
yapılan mevcut araştırmalara katkı sağlaması amaçlanmıştır. Doğrusal olmama ve yapısal kırılmaları hesaba katan bir birim kök testi yardımıyla sağlık harcamaları dinamiklerinin daha doğru bir değerlendirmesi yapılabileceği ve dört alternatif arasından en uygun tahmin yöntemini belirlemek için yapılan F-testleri sonucunda, FADF-SB prosedürünün en iyi yaklaşım olduğu görülmüştür. Yapılan ekonometrik analiz sonucunda Kanada, Danimarka, İrlanda ve Yeni Zelanda ülkeleri dışındaki 17 OECD ülkesi (Avustralya, Avusturya, Belçika, Finlandiya, Almanya, İzlanda, Japonya, Kore, Hollanda, Norveç, Portekiz, İspanya, İsveç, İsviçre, Türkiye, Birleşik Krallık, ABD) için yakınsama hipotezinin geçerli olduğu sonucuna ulaşılmıştır. Elde edilen bu bulgu, Pekkurnaz (2015) ve Payne vd. (2015)'nin çalışmalarında elde ettikleri bulgular ile benzerlik göstermektedir.

Çalışmadan elde edilen sonuçlar, birim kök testlerinde yapısal kırılmaları ve doğrusal olmama durumunu dikkate almanın önemini vurgulamaktadır. Bu bağlamda, politika yapıcıların yapısal değişiklikleri ve doğrusal olmama durumunu dikkate almayan yakınsama testlerine güvenirken dikkatli olmaları gerekmektedir. Çünkü bu durum yanıltıcı sonuçlara ve dolayısıyla yanlış politika önlemlerine ve gereksiz müdahalelere yol açabilir. Sonuçlar ayrıca sağlık harcamaları düşük seviyede olan ülkelerin, yüksek sağlık harcamalarına sahip ülkelere yakınsadığını ortaya koymaktadır. OECD ülkeleri arasında sağlık harcamalarının yakınsaması, bu ülkelerin sağlık hizmetlerinde daha etkin bir şekilde harcama yapmasını sağlayarak ekonomik büyümeyi teşvik edebilmektedir. Yakınsama hipotezinin geçerli olmadığı ülkelerde ise sağlık hizmetlerinin sürekli iyileştirilmesi yoluyla yakınsamayı destekleyen politikalara ihtiyaç bulunmaktadır. 


\section{KAYNAKÇA}

Akarsu, G., Cafri, R., \& Bidirdi, H. (2019). OECD Ülkelerinde Sağlık Harcamalarının Kamu-Özel Bileşenleri Yakınsıyor Mu? Doğrusal Olmayan Panel Birim Kök Testi Bulguları. Sosyoekonomi, 27.

Albulescu, C., Oros, C., \& Tiwari, A. K. (2017). Is there any convergence in health expenditures across EU countries?. Economics Bulletin, 37(3), 2095-2101.

Apergis, N., Chang, T., Christou, C., \& Gupta, R. (2017). Convergence of health care expenditures across the US States: A reconsideration. Social Indicators Research, 133(1), 303-316.

Aslan, A. (2008), "Convergence of Per Capita Health Care Expenditures in OECD Countries", MPRA Paper 10592, University Library of Munich, Germany.

Clemente, J., Lázaro-Alquézar, A., \& Montañés, A. (2019). US state health expenditure convergence: A revisited analysis. Economic Modelling, 83, 210-220.

Evans, P. and Karras, G. (1996) Convergence revisited, Journal of Monetary Economics, 37, $249-65$. doi:10.1016/0304-3932(96)01250-0.

Furuoka, F., “A New Approach to Testing Unemployment Hysteresis”, Empirical Economics, 2017, 53(3), ss. 1253-1280.

Hitiris, T., \& Nixon, J. (2001). Convergence of health care expenditure in the EU countries. Applied Economics Letters, 8(4), 223-228.

Indicators, OECD (2019). Health at a Glance.

Kerem, K. \& T. Puss \& M. Viies \& R. Maldre (2008), "Health and Convergence of Health Care Expenditure in EU”, International Business and Economics Research Journal, 7(3), 29-44.

Lau, C. K. M., Fung, K. W. T., \& Pugalis, L. (2014). Is health care expenditure across Europe converging? Findings from the application of a nonlinear panel unit root test. Eurasian Business Review, 4(2), 137 156.

Narayan, P. K. (2006) Examining structural breaks and growth rates in international health expenditures, Journal of Health Economics, 25, 877-90. doi:10.1016/j.jhealeco.2005.12.001.

Narayan, P. K., \& Popp, S. (2011). A nonlinear approach to testing the unit root null hypothesis: an application to international health expenditures. Applied Economics, 44(2), 163-175.

Narayan, P.K. (2007), “Do Health Expenditures 'Catch-up'? Evidence from OECD countries", Health Economics, 16(10), 993-1008.

Nghiem, S. H., \& Connelly, L. B. (2017). Convergence and determinants of health expenditures in OECD countries. Health Economics Review, 7(1), 1-11.

Nixon, J. (1999). Convergence analysis of health care expenditure in the EU countries using two approaches. The University of York discussion papers in economics, 3.

Odhiambo, S. A., Wambugu, A., \& Kiriti-Ng'ang'a, T. (2015). Convergence of health expenditure in SubSaharan Africa: Evidence from a dynamic panel. Journal of Economics and Sustainable Development, Vol.6, No.6.

Panopoulou, E., \& Pantelidis, T. (2012). Convergence in per capita health expenditures and health outcomes in the OECD countries. Applied Economics, 44(30), 3909-3920.

Payne, J. E., Anderson, S., Lee, J., \& Cho, M. H. (2015). Do per capita health care expenditures converge among OECD countries? Evidence from unit root tests with level and trend-shifts. Applied Economics, 47(52), $5600-5613$.

Pekkurnaz, D. (2015), “Convergence of Health Expenditure in OECD Countries: Evidence from a Nonlinear Asymmetric Heterogeneous Panel Unit Root Test", Journal of Reviews on Global Economics, 4, 76-86.

Quah, D. (1996) Empirics for economic growth and convergence European Economic Review, 40, $1353-75$. doi:10.1016/0014-2921(95)00051-8.

Rassekh, F. (1998). The convergence hypothesis: History, theory, and evidence. Open economies review, 9(1), 85-105.

Sala-i-Martin, X. (1996) The classical approach to convergence analysis, Economic Journal, 106, 1019-36.

Solow, R. (1956) A contribution to the theory of economic growth, Quarterly Journal of Economics, 70, 65-94.

Şahin, D. (2018) Türkiye ve Mena ülkelerinde sağlı̆̆ın yakınsaması: Panel Birim Kök Testi. Karadeniz Teknik Üniversitesi Sosyal Bilimler Enstitüsü Sosyal Bilimler Dergisi, 8(16), 235-252.

Tülümce, Y.S. \& F. Zeren (2013), “OECD Ülkelerinde Sağlı̆̆ın Yakınsamasının Analizi: Panel Birim Kök Testi”, Süleyman Demirel Üniversitesi İktisadi ve İdari Bilimler Fakültesi Dergisi, 18(2), 287-300.

Wang, Z. (2009). The convergence of health care expenditure in the US states. Health Economics, 18(1), 55-70.

Zhang, G., Zhang, L., Wu, S., Xia, X., \& Lu, L. (2016). The convergence of Chinese county government health expenditures: capitation and contribution. BMC health services research, 16(1), 408. 